\title{
The Role of the Heart Failure Specialist: Benefits for Both the Patient and the Cardiology Community
}

\author{
Livia A. Goldraich, ${ }^{10}$ Jefferson L. Vieira, ${ }^{2}$ Nadine Clausel/ ${ }^{10}$ \\ Hospital de Clínicas de Porto Alegre, ${ }^{1}$ Porto Alegre, RS - Brazil \\ Hospital de Messejana Dr. Carlos Alberto Studart, ${ }^{2}$ Fortaleza, CE - Brazil
}

In recent decades, the advancement of knowledge of cardiovascular diseases has been remarkable. Heart failure (HF) has a prominent role among the conditions of greatest epidemiological relevance for the population, given its high prevalence and incidence worldwide, including Brazil. ${ }^{1-4}$ Thus, mastery of this condition is key to cardiologist training. However, the understanding of the complexity of the different diseases and pathophysiological mechanisms potentially involved in the development, progression, and prognosis of HF has advanced, and a broad and intricate spectrum of therapeutic options has emerged, especially in the past two decades. These advances allowed a significant improvement in the clinical outcomes of HF patients; however, as knowledge and consequent therapeutic challenges became more complex, it was clear that a new type of training and expertise in the field of Cardiology was needed.

The American Heart Association (AHA) and the European Society of Cardiology (ESC) were the first to encourage the growth and strengthening of the HF specialty, with the creation of study groups, departments, and journals focused on this condition. ${ }^{5-7}$ Several specific HF congresses have been organized and brought together a growing number of participants for about 20 years. Concomitantly, several cardiology centers of worldwide relevance have developed fellowship programs in HF and heart transplantation, many of which more recently also cover mechanical circulatory support. Finally, certification examinations for HF specialist by the American Board of Internal Medicine (ABIM) and the ESC Heart Failure Association were created in 2013 and 2014, respectively. ${ }^{5,8}$ In 2020, an expert consensus of the American College of Cardiology (ACC) together with the Heart Failure Society of America (HFSA) and the International Society for Heart and Lung Transplantation (ISHLT) introduced a list of requirements for HF specialist training, based on the core competencies of the Accreditation Council for Graduate Medical Education (ACGME). ${ }^{9}$ This document outlines, in particular, the expectations for physicians who treat advanced HF patients or heart transplant recipients, and

\section{Keywords}

Heart failure/prevalence; Specialization; Learning; Continuity of Patient Care; Epidemiology; Cross-Sectional Studies.

Mailing Address: Nadine Clausell •

Serviço de Cardiologia - Hospital de Clínicas de Porto Alegre - Rua Ramiro

Barcelos, 2350. CEP 90035-003, Porto Alegre - RS - Brazil

E-mail: nclausell@hcpa.edu.br

Manuscript received April 28, 2020, revised manuscript May 30, 2020 accepted May 30, 2020 recommends specific skills in mechanical circulatory support, cardiac resynchronization therapy, heart transplantation, and pulmonary hypertension. The authors also recommend that there be a maintenance of certification process based on participation in continuing medical education programs and collaboration with national databases and registries. ${ }^{10}$ Table 1 exemplifies and adapts the HF training model used at Brigham and Women's Hospital, Harvard University, Boston, United States.

In Brazil, although the Department of Heart Failure (DEIC) at Brazilian Society of Cardiology (SBC) completed 20 years in 2020 and ran its 19th annual congress in 2021, the HF specialty still lacks recognition among cardiologists, noncardiologists, multidisciplinary staff, health administrators, and patients and their caregivers. ${ }^{11}$ Also, there is a limited number of specific training options, although some Brazilian centers grant HF specialization degrees with an additional year of training, following completion of cardiology residency. Some institutions have also designed specific medical residency programs accredited by the Brazilian Ministry of Education or Ministry of Health in the field of heart transplantation, which have included comprehensive content on HF and its different dimensions. ${ }^{12} \mathrm{HF}$ training programs currently available in Brazil are shown in Table 2.

These training programs aim to qualify the cardiologist to care for patients in all stages of HF, especially those with advanced disease who often require hospitalization, vasoactive drugs, invasive hemodynamic monitoring, mechanical circulatory assist devices, or heart transplantation. Technical skills and specific procedures may vary in the different HF training programs depending on the characteristics of the settings where graduates will work. Furthermore, these programs aim to prepare HF professionals to work in clinical settings collaboratively, seeking to integrate the different cardiology specialties that are important in the evaluation and care of HF patients. The advancement in the field of HF has expanded the scope of action of HF specialists, which is not restricted to the management of patients requiring advanced therapies and may currently involve evaluation and treatment of diseases of complex etiology, comorbidities, or pulmonary hypertension; cardio-oncology; multimodality imaging in cardiology; electrophysiology; cardiac rehabilitation; genetics; cardiac intensive care; and palliative care. It is worth noting that these physicians should be prepared to play a care coordinator role for HF patients in situations that very often include professionals from different disciplines, such as making prompt and critical decisions involved in the management of cardiogenic shock or chronic illnesses. Additionally, HF specialists play a growing role for improving research in this field.

DOI: https://doi.org/10.36660/abchf.20210002 


\section{Editorial}

Table 1 - Adapted list of specific competencies and skills that are included in the Advanced Heart Failure, Heart Transplantation, and Ventricular Assist Device fellowship program at Brigham and Women's Hospital, Harvard University (Boston, United States)

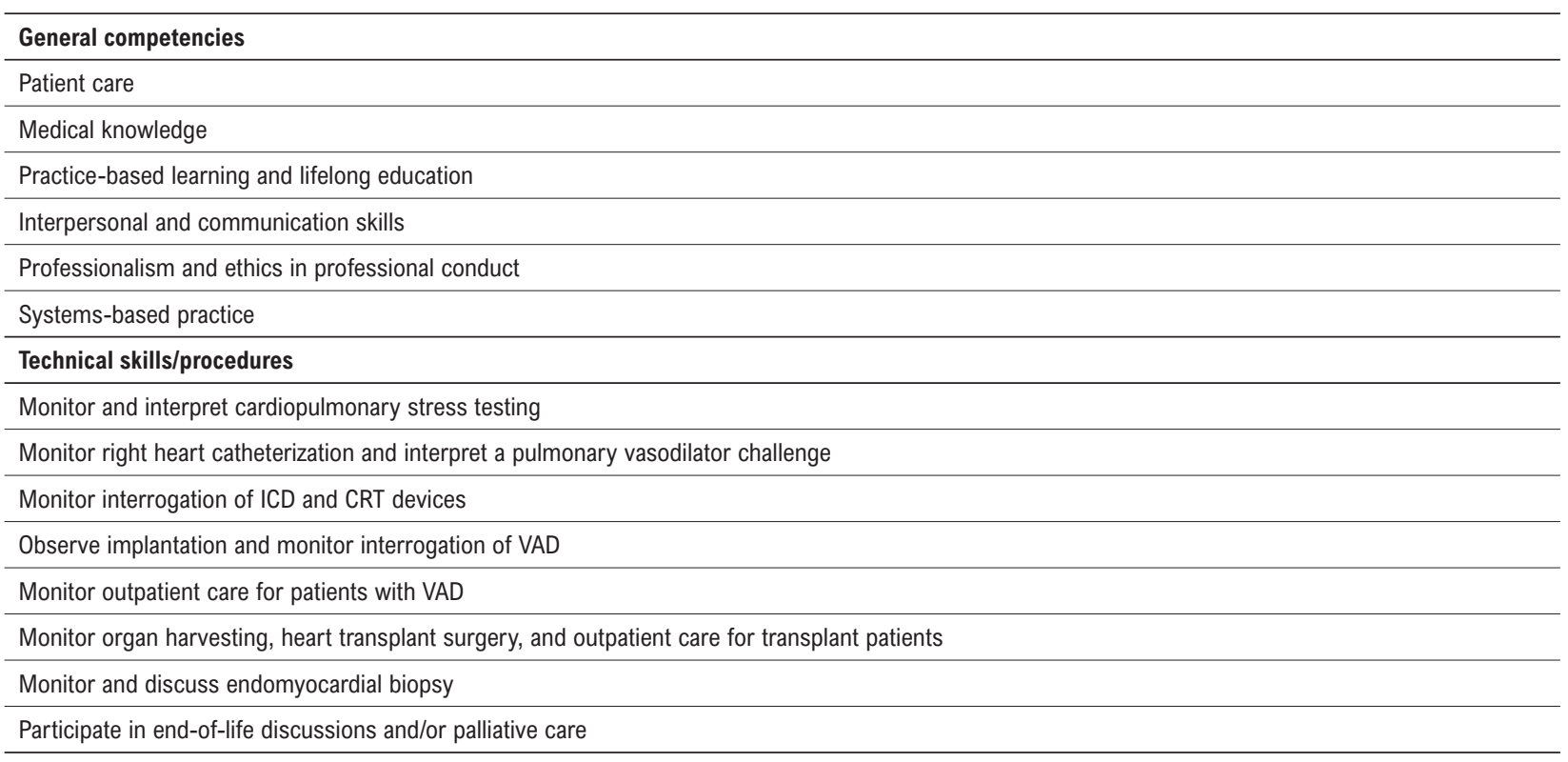

CRT, cardiac resynchronization therapy; ICD, implantable cardioverter-defibrillator; VAD, ventricular assist device.

Table 2 - Medical residency programs and specialization degrees in advanced heart failure and heart transplantation available in Brazil

\begin{tabular}{l}
\hline 1. Instituto Dante Pazzanese de Cardiologia \\
\hline Continuing Education on Heart Transplant in Adults \\
\hline 2. Sociedade Beneficente Israelita Brasileira Hospital Alberto Einstein \\
\hline Continuing Education on Transplant and Heart Failure \\
\hline 3. Instituto do Coração (Incor) - HC-FMUSP \\
\hline Specialized Complementation Program: Congestive Heart Failure and Ventricular Assist Devices \\
Heart Transplant Residency \\
\hline 4. Universidade Federal de São Paulo - UNIFESP \\
\hline Medical Residency at Escola Paulista de Medicina \\
Optional year: Heart Transplant \\
\hline 5. Hospital de Clínicas de Porto Alegre \\
\hline Medical Residency - Additional year: Heart Transplant \\
\hline 6. Instituto de Cardiologia do Rio Grande do Sul/Fundação Universitária de Cardiologia \\
\hline Medical Residency - Additional year: Heart Transplant Education \\
\hline 7. Instituto de Medicina Integral Professor Fernando Figueira - IMIP \\
\hline Specialized Complementation Program - COMESP in Heart Transplant and Advanced Heart Failure \\
\hline Source: Mesquita ET, Mendes AP, Moura L, Figueiredo Neto JA, Marcondes-Braga FG, Bacal F, Moreira MDCV, Clausell NO. The Challenges of Heart \\
Failure Yesterday, Today and Tomorrow and the 20 Years of DEIC. Arq Bras Cardiol. 2021 Feb;116(2):359-362.12
\end{tabular}

In several countries and, most likely, in Brazil, family physicians, geriatricians, and general practitioners provide care to a large number of HF patients, in addition to general cardiologists. ${ }^{13}$ In countries where the HF specialty is developed and recognized, this care pathway is based on an adequate flow of referral and counter-referral between nonspecialists and specialists, with significant interactions in the shared care model. ${ }^{10,14}$ Nonetheless, several studies suggest that care provided by HF specialists improves clinical outcomes, including reduced hospitalizations and increased survival. ${ }^{15,16}$ 
Preliminary data from a research project conducted by our group, with support from SBC, indicate that HF patients may account for 25 to $50 \%$ of all patients treated by many general cardiologists; however, referral to HF specialists still seems to be infrequent. Limited recognition by both peers and patients was one of the main aspects considered by HF specialists to be barriers to the development of the specialty in Brazil (unpublished data). Our data suggest that, despite the efforts made in recent years to highlight the importance of the HF specialty in the cardiac care scenario in Brazil, there is still a long way to go so that this specialist is properly recognized and can positively impact the outcomes of HF patients.

In conclusion, given the increasing prevalence of $\mathrm{HF}$ and limited access to specialized care, more institutions should encourage physicians to train and become HF specialists. Additionally, it seems a good time to work on the idea that the presence and action of the HF specialist in a cardiology group or center will contribute to the growth of the field, leading to strengthened shared management practices with general cardiologists and potentially expanding the validation and the call for other cardiac specialties and multidisciplinary staff. With the inclusion of HF specialists, health managers and researchers will find a wide scope of practices to improve care and innovation processes, respectively. Finally, recruiting HF specialists to work on institutions will not only benefit the patients in terms of clinical outcomes but also add quality and progress through interdisciplinarity, which is a strong characteristic of contemporary care for these patients (Figure 1).

\section{Author contributions}

Writing of the manuscript: Goldraich LA, Vieira JL, Clausell N.

\section{Potential Conflict of Interest}

No potential conflict of interest relevant to this article was reported.

\section{Sources of Funding}

There were no external funding sources for this study.

\section{Study Association}

This study is not associated with any thesis or dissertation work.

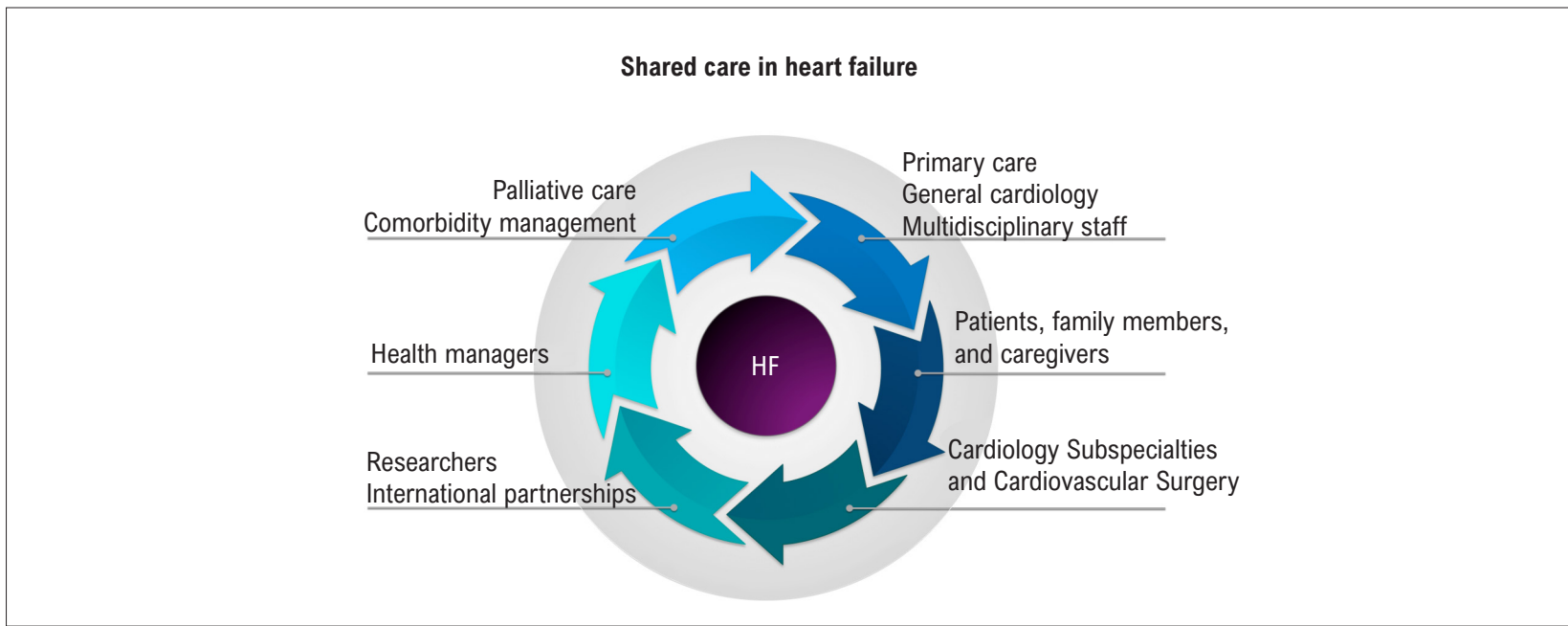

Figure 1 - Graphical representation of interdisciplinarity in contemporary care of patients with heart failure. HF: heart failure. 


\section{References}

1. Virani SS, Alonso A, Aparicio HJ, Benjamin EJ, Bittencourt MS, Callaway CW, et al. Heart Disease and stroke statistics-2021 update: a report from the American Heart Association. Circulation. 2021;143(8):e254-e743.

2. Stevens B, Pezzullo L, Verdian L, Tomlinson J, George A, Bacal F. The Economic Burden of Heart Conditions in Brazil. Arq Bras Cardiol. 2018;111(1):29-36.

3. Fernandes ADF, Fernandes GC, Mazza MR, Knijnik LM, Fernandes GS, Vilela AT, et al. A 10-year trend analysis of heart failure in the less developed Brazil. Arq Bras Cardiol. 2020;114(2):222-31.

4. Conrad N, Judge A, Tran J, Mohseni H, Hedgecott D, Crespillo AP, et al. Temporal trends and patterns in heart failure incidence: a population-based study of 4 million individuals. Lancet. 2018;391(10120):572-80.

5. Jessup M, Drazner MH, Book W, Cleveland Jr JC, Dauber I, Farkas S, et al. 2017 ACC/AHA/HFSA/ISHLT/ACP Advanced Training Statement on Advanced Heart Failure and Transplant Cardiology (Revision of the ACCF/AHA/ACP/HFSA/ISHLT 2010 Clinical Competence Statement on Management of Patients With Advanced Heart Failure and Cardiac Transplant): a Report of the ACC Competency Management Committee. Circ Heart Fail. 2017;10(6):e000021.

6. Westenbrink BD, Brugts JJ, McDonagh TA, Filippatos G, Ruschitzka F, Laake LW. Heart failure specialization in Europe. Eur J Heart Fail. 2016;18(4):347-9.

7. Konstam MA Executive Council of the Heart Failure Society of America. Heart failure training: a call for an integrative, patient-focused approach to an emerging cardiology subspecialty. J Am Coll Cardiol. 2004;44(7):1361-2.

8. McDonagh TA, Gardner RS, Lainscak M, Nielsen OW, Parissis J, Filippatos $\mathrm{G}$, et al. Heart failure association of the European Society of Cardiology specialist heart failure curriculum. Eur J Heart Fail. 2014;16(2):151-62.

9. Accreditation Council for Graduate Medical Education. ACGME Program Requirements for Graduate Medical Education in Advanced Heart Failure and Transplant Cardiology [citado 07 Março de 2021]. Disponível em https://www.acgme.org/Portals/0/PFAssets/ProgramRequirements/159 AdvancedHeartFailureTransplantCardiology_2020. pdf?ver=2020-02-14-153940-843.

10. Yancy CW, Drazner MH, Coffin ST, Cornwell 3rd W, Desai S, Erwin 3rd JP, et al. 2020 ACC/HFSA/ISHLT Lifelong Learning Statement for Advanced Heart Failure and Transplant Cardiology Specialists: a Report of the ACC Competency Management Committee. J Am Coll Cardiol. 2020;75(10):1212-30.

11. Scheffer M, Cassenote A, Guilloux AGA, Miotto BA, Mainardi GM, Matijasevich A, etal. Demografia Médica no Brasil 2018. São Paulo: FMUSP; 2018. 286 p.

12. Mesquita ET, Mendes AP, Moura L, Figueiredo Neto JA, Marcondes-Braga FG, Bacal F, et al. The Challenges of Heart Failure Yesterday, Today and Tomorrow and the 20 Years of DEIC. Arq Bras Cardiol. 2021;116(2):359-62.

13. Verhestraeten C, Weijers G, Debleu D, Ciarka A, Goethals M, Droogmans $S$, et al. Diagnosis, treatment, and follow-up of heart failure patients by general practitioners: a Delphi consensus statement. PLoS One. 2020;15(12):e0244485.

14. Baumwol J. "I Need Help"-A mnemonic to aid timely referral in advanced heart failure. J Heart Lung Transplant. 2017;36(5):593-4.

15. Griffin EA, Wonderling D, Ludman AJ, Al-Mohammad A, Cowie MR, Hardman SMC, et al. Cost-effectiveness analysis of natriuretic peptide testing and specialist management in patients with suspected acute heart failure. Value Health. 2017;20(8):1025-33.

16. Morton G, Philip L, Gilpin T, Chan PE, Guha K, Kalra PR. Does specialist review for patients with suspected heart failure predict better outcomes? An observational study on the utility of compliance with NICE guidelines. BMJ Open. 2018;8(8):e021856. 